\title{
O TRABALHO COMO FORMAÇÃO E DEFORMAÇÃO HUMANA EM HEGEL E MARX
}

\author{
Eduardo F. Chagas ${ }^{1}$
}

\begin{abstract}
Resumo: Aponto, inicialmente, uma positividade do trabalho em Hegel, que é recepcionada criticamente por Marx nos seus Manuscritos Econômico-Filosóficos (Ökonomischphilosophische Manuskripte) (1844). Hegel defende na Fenomenologia do Espírito (Phänomenologie des Geites) que, pela mediação do trabalho, a consciência-de-si se torna consciência-para-si, autoconsciência, ou seja, que o trabalho forma, educa, a consciência. Marx vê na Fenomenologia do Espírito, de Hegel, uma grande realização, dado que Hegel concebe a "autocriação" do homem como um processo, porque compreende a essência do trabalho e porque evidencia o homem objetivo "como resultado de seu próprio trabalho", mas Hegel reconhece só o lado positivo do trabalho, mas não o seu aspecto negativo. Ao contrário de Hegel, há em Marx uma concepção dupla do trabalho: tanto em seu sentido afirmativo (o trabalho livre e consciente, trabalho útil-concreto, vivo), quanto negativo (trabalho estranhado, trabalho assalariado, trabalho abstrato, morto).
\end{abstract}

Palavras-chave: Trabalho em Hegel e Marx; Positividade e Negatividade do Trabalho em Hegel e Marx; Formação e Deformação Humana em Hegel e Marx.

Abstract: I reveal, initially, a positivity of work in Hegel's ideas, which is approved critically in his Economic and Philosphic Manuscripts (Ökonomisch-philosophische Manuskripte) (1844). In Phenomenology of Mind (Phänomenologie des Geites), Hegel supports that, by mediation through work, self-conciousness becomes consciousness-for-itself, auto-consnciousness. Hegel indicates that work educates and forms consciousness. Marx admits that Hegel's Phenomenology of Mind is a seminal oeuvre, in view of the fact that Hegel conceives the "selfcreation" of individual as a process, because he considers the essence of work and because he evinces the objective individual "as the result of his or her own work". However, Hegel only focuses on the positive aspects of work, excluding the importance of its negative elements. In contrast to Hegel, there is in Marx ideas a double conception of work: in its affirmative aspect (the free work, living labor, useful and concrete labor), and in its negative concept (alienated labor, wage labor, abstract and dead labor).

Keywords: Work in Hegel and Marx; Positivity and Negativity of Work in Hegel and Marx; Human Formation and Deformation in Hegel and Marx.

\footnotetext{
${ }^{1}$ Graduado em Filosofia pela Universidade Estadual do Ceará (UECE, 1989), Mestrado em Filosofia pela Faculdade de Filosofia e Ciências Humanas (FAFICH) da Universidade Federal de Minas Gerais (UFMG, 1993) e Doutorado em Filosofia pela Universität von Kassel (KASSEL, ALEMANHA, 2002). É professor efetivo (associado) do Curso de Filosofia e do Programa de Pós-Graduação em Filosofia da Universidade Federal do Ceará (UFC) e professor colaborador do Programa de Pós-Graduação em Educação Brasileira da FACED - UFC. Coordenador do Grupo de Estudos Marxistas - GEM -, vinculado ao Eixo Marxismo, Teoria Crítica e Filosofia da Educação, e ao Programa de Pós-Graduação em Educação Brasileira da FACED - UFC. Orientador do Programa Jovens Talentos/CNPQ. Atualmente, é pesquisador bolsista de produtividade CNPQ, é membro da Internationale Gesellschaft der FeuerbachForscher (Sociedade Internacional Feuerbach) e dedica suas pesquisas ao estudo da filosofia política, da filosofia de Hegel, do idealismo alemão e de seus críticos Feuerbach, Marx, Adorno e Habermas. E-mail: ef.chagas@uol.com.br. Homepage: http://efchagasufc.wordpress.com/. Editor da Revista Dialectus (http://www.revistadialectus.ufc.br/index.php/RevistaDialectus/about/editorialPolicies\#sectionPolicies).
} 
Apresento, neste artigo, uma concepção dupla do trabalho em Marx, destacando, inicialmente, a positividade do trabalho em Hegel, que será recepcionada por Marx tanto no seu sentido afirmativo (trabalho livre e consciente, trabalho útil-concreto, vivo) quanto negativo (trabalho estranhado, trabalho abstrato, morto). Há uma visão positiva, otimista, de Hegel acerca do trabalho no capítulo IV, seção A, "Independência e Dependência da Consciência-de-si - Dominação e Servidão -, de sua Fenomenologia do Espírito (Phänomenologie des Geites) (1806). Hegel defende que, pela mediação do trabalho, a consciência-de-si se torna consciência-para-si, autoconsciência, ou seja, que o trabalho forma, educa, a consciência, embora isto não se dê de forma imediata. No início desse capítulo, Hegel deixa claro que o servo (der Knecht) é a consciência de si que só trabalha, e pelo trabalho ele transforma a coisa, mas não pode consumi-la ou "acabar com ela até a aniquilação" 355 porque ela é para ele autônoma, exterior, e não lhe pertence, ficando transferida ao senhor. Este, ao contrário, nega ou acaba pela mediação do trabalho do servo com a resistência de um mundo exterior, com a independência da coisa, se apropria dela, aquietando seu desejo no gozo. Cabe ao senhor apenas usufruir, gozar, dos frutos que o servo produz, pois, ao introduzir o servo entre ele e a coisa, consegue satisfazer o seu desejo, deixando o lado da dureza das coisas, de sua independência, ao servo, que só trabalha. O senhor (der Herr) vem a ser senhor, quer dizer, só obtém a sua "autonomia", o seu reconhecimento como senhor mediante uma outra consciência de si, a da consciência do servo (knechtische Bewusstsein). Esta se revela, no entanto, como inessencial em dois momentos fundamentais: 1. quando elabora a coisa, mas não pode se apropriar dela, e 2. quando fica dependente de seu seraí imediato, natural-biológico. Nesses dois momentos, o servo "não pode assenhorar-se

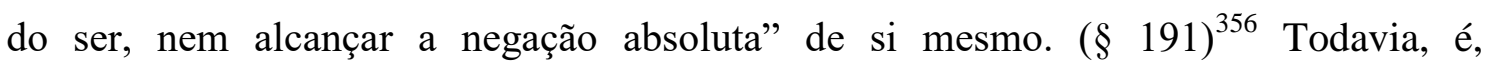
precisamente, a partir daqui que se começa a apresentar o movimento da consciência servil rumo ao seu reconhecimento, pois aqui já está presente o momento, em estado nascente, em que esta consciência se nega enquanto consciência puramente servil, enquanto ser servo, na medida em que a sua operação, o seu fazer, corresponde justamente ao próprio fazer do senhor, que é o ser-para-si, a essência ou a potência negativa, que reduz as coisas ao nada, a vida a um fenômeno, a um dado negativo. Mas,

\footnotetext{
${ }^{355}$ Hegel, G. F. W. Phänomenologie des Geistes. Hauptwerke in sechs Bänden, Vol. 2 Organização de Wolfgang Bonsiepen e Reinhard Heede. Hamburgo: Wissenschaftliche Buchgesellschaft Darmstadt, 1999 , p.113.

${ }^{356}$ Ibid., p. 113.
}

\begin{tabular}{|l|l|l|l|l|}
\hline Q & Dovista \\
\hline
\end{tabular}


para que haja o reconhecimento pleno, efetivo, da consciência servil falta ainda um momento substancial, a saber, o reconhecimento mútuo, recíproco, a reciprocidade do fazer entre as consciências, obtendo aquilo que o senhor faz sobre si o que também faz sobre o servo, e o que o servo faz consigo, o faça também com o outro. Como o que um faz consigo não é o mesmo o que faz sobre o outro, nessa ausência o que se tem aqui, no dizer de Hegel, é somente um reconhecimento unilateral, parcial e desigual.

É necessário chamar aqui a atenção para o fato de que o senhor, ao ter chegado à certeza de si em sua dominação (Herrschaft) através de uma consciência dependente e inessencial, não obtém a verdade de si mesmo, não tem um reconhecimento legítimo advindo de outras consciências livres, porque o seu objeto (a liberdade, a consciência de si) "não corresponde ao seu conceito"357 (ao reconhecimento recíproco), o qual pressupõe uma outra consciência também livre, independente (§ 192). Na verdade, o senhor alcança sua autoconsciência através de uma mediação inumana (da consciência servil), pois o objeto, através do qual ele se afirma, não é, a rigor, uma outra consciência. Assim, o reconhecimento não se dá por meio de uma consciência livre, mas de uma consciência dependente e, portanto, coisificada Quer dizer, a consciência do servo constitui objeto em que o senhor deveria ter a verdade de sua própria certeza, porém, como ela não é autônoma, livre, tampouco pode proceder a este ato de reconhecimento: assim, o movimento que parte do senhor se detém, pois a consciência do servo é a verdade do senhor, mas ela própria não tem aqui por parte do senhor nenhuma verdade. Portanto, o senhor não está certo de si como verdade, pois que sua verdade (Wahrheit) é, de fato, o agir "secundário", "inessencial”, da consciência servil. Esta aparecia, de início, como se estivesse fora do senhor, exterior a ele, e não como a verdade dele ( $§ 193$ ). Mas, assim como a dominação mostra ser, em sua essência, o contrário do que é (o senhor como servo do servo), assim também a servidão (Knechtschaft) irá se revelar como o inverso de sua apresentação imediata (o servo como senhor do senhor), pois ela, concentrada em si, em exterioridade aparente ao essencial que advém do senhor, ao se desdobrar sobre si mesma, manifestará sua verdadeira autonomia e, por conseguinte, se mostrará não só como a verdade da certeza do senhor, como também a verdade da consciência de si enquanto consciência autêntica e independente. Até aqui, a consciência servil apresentou-se a partir do comportamento da dominação; agora, é necessário considerá-la em-si e para-si mesma. De início, ela

${ }^{357}$ Ibid., p. 114.

\begin{tabular}{|l|l|l|l|l|}
\hline Qovista Dialectus & Ano 3 & n. 8 & Janeiro - Agosto 2016 & p. 16-32 \\
\hline
\end{tabular}


tem a verdade (a sua essência, a liberdade) exterior a ela, como um ser ideal de liberdade, e toma o senhor como uma consciência independente e essencial; entretanto, ao fazer a experiência de sua pura negatividade, ela já tem em si mesma a verdade da consciência independente, ou seja, que ela é, em verdade, autônoma, como o senhor. Isto se dá, quando ela sente a angústia, não sobre isto ou aquilo, não sobre este ou aquele instante, mas sobre a integridade de sua essência, ao sentir o medo da morte, do "senhor absoluto". Diante do medo frente ao senhor, a consciência servil se dissolve interiormente, treme em sua raiz e percebe a totalidade de seu ser, e tudo o que é fixo nela desvencilha ( $§$ 194). Esse processo de dissolução, o fluidificar-se de todo o subsistir da vida imediata e orgânica, é o momento da negatividade da consciência de si serva. Esta consciência recupera seu ser-para-si, dando-se conta de que o medo que experimenta é expressão da negatividade radical que se encontra nela, como também se realiza por meio dela. Presente nela, embora ela não se tenha dado conta, é esta negatividade, este ser-para-si radical, que a constitui enquanto consciência autônoma e livre. Experimentando o seu ser-para-si que considerava estranho a ela, vai a consciência servil tomando convicção de que nada "estranho" pode resistir à potência negativa que reside nela, e que o serviço, que parecia expressar sua sujeição, se converte naquilo mediante o qual traduzirá o seu poder sobre o mundo. Mas tal negatividade, tal dissolução, se implementa, efetivamente, quando a consciência servil vai superando, pelo trabalho, todos os momento de sua aderência ao ser-aí determinado, a uma existência puramente física, "animal".

No medo da morte (in der Todesfurcht), no temor ao senhor, se dá, sem dúvida, diz Hegel, o início da sabedoria, ou seja, se inicia a dissolução das determinações naturais, do ser-aí, que implicam a consciência servil (das knechtische Bewusstsein). Mas isto é só o começo, pois tal consciência ainda não realizou para si mesma toda a verdade vivida nesse medo absoluto, visto que é só por meio do trabalho (Arbeit) como um processo de auto-reflexão, de auto-objetivação, que ela se torna, por conseguinte, um ser-para-si independente, toma consciência de si mesma. Deste modo, o trabalho permite à consciência servil assegurar o seu poder sobre o mundo, superar o seu medo, ao provar a si mesma que o mundo não lhe é estranho e a dar efetividade à negatividade absoluta que reside nela como consciência de si. Se, no momento da dominação, a consciência sevil se comportava de forma inessencial para com a coisa, que se mantinha como algo independente dela e não apropriada por ela, a consciência do senhor

\begin{tabular}{|c|c|c|c|c|}
\hline Q Ronita Dialectus & Ano 3 & n. 8 & Janeiro - Agosto 2016 & p. 16-32 \\
\hline
\end{tabular}


(Herrschaftssbewusstsein), ao contrário, se apropria dela, satisfazendo, assim, completamente o seu desejo. Mas o gozo do senhor é puramente negativo, uma negação completa da coisa, pois, para saciar seu desejo, precisa constantemente pôr o objeto e, imediatamente, negá-lo, ficando, pois, "sem mescla" com o subsistir do objeto, sem nexo com o dado objetivo e independente da realidade. Nessa negação constante do objeto, a satisfação, o gozo, do senhor é, por esse motivo, evanescente, está em estado permanente de desaparecimento. A consciência servil, ao contrário, pelo trabalho não só nega, como o senhor, mas também constrói o objeto, por isso o trabalho é, para Hegel, desejo refreado, um desvanecer contido, criador: ele não só consome o objeto, mas também o repõe, o forma, de tal maneira que o objeto permanece para quem trabalha. Assim, pode-se dizer que o objeto natural foi superado, ao ter sido formado, mas ao mesmo tempo não foi completamente aniquilado, mas conservado. Hegel chama aqui o trabalho de formação (Bildung), de uma operação formativa, pois a consciência, ao formar o objeto, forma, pois, a si mesma, ou seja, ao se exteriorizar, se concretizar no objeto, ela se imprime, se vê nesse objeto exteriorizado, contempla a si mesma como a verdade na forma dos objetos trabalhados e se torna um ser-para-si; ou seja, ao ver no produto a imagem objetiva de sua negatividade criadora, ao ter o objeto como obra sua, ao apreendê-lo pelo trabalho, ela apreende a si mesma, chegando, assim, à consciência de si mesma (§ 195), à emancipação (Emanzipation) e à autorealização (Selbstverwirklichung).

O trabalho, enquanto formação, implica dois aspectos fundamentais, a saber: a) um positivo, pois é pelo trabalho que a consciência servil se torna um ser-para-si, autoconsciente, e b) um negativo, que é em relação ao medo frente à natureza, quer dizer, não que o trabalho seja em si negativo, pois é também por ele que a consciência servil supera esse medo, isto é, elimina o seu pavor diante da exterioridade de um mundo natural adverso, de uma realidade objetiva que lhe ameaça, que lhe parece, inicialmente, estranha e hostil (§ 196). O trabalho permite à consciência servil construir o objeto, de tal forma que este deixa de ser um "negativo alheio" e passa a ser algo dela, um algo, através do qual ela se torna, para ela mesma, um ser-para-si, atinge a consciência de si mesma. No trabalhar, no formar (in dem formieren), "o ser-para-si se torna para ele como o seu próprio, e assim chega à consciência de ser ele mesmo em si e

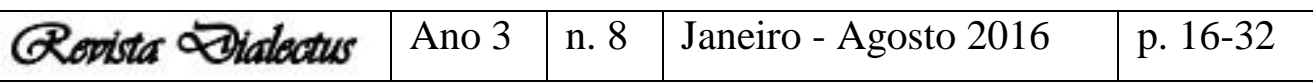


para si. $" 358$ Portanto, para Hegel, é no trabalho que a consciência, ao se exteriorizar, se reencontra, atinge a sua liberdade, a sua verdade e o seu sentido próprio de ser um serpara-si. Para chegar até aqui, foram necessários, então, os três momentos: a) o medo primordial; b) o serviço (a obediência) e c) a formação, o trabalho. Tais momentos são inseparáveis, pois, sem o medo, o trabalho não imprime a forma da consciência nas coisas; sem disciplina do serviço e da obediência, o medo permanece formal, vazio, não abrangendo toda a realidade do ser, e sem a atividade formadora, sem o trabalho, o medo permanece como exterior e mudo, e a consciência não chega à consciência de si, a autoconsciência como essência livre. Para que a consciência não fique mergulhada no ser-aí determinado, na coisa imediata, e a liberdade deixe de ser uma mera liberdade abstrata no interior da servidão, é necessário que todos os conteúdos da consciência natural sejam abalados, desmoronados. Sem isto, a consciência não se torna universal, não alcança uma formação plena, ficando restrita a uma consciência limitada, presa aos interesses particulares da vida, que possui apenas uma certa habilidade particular, que domina alguma coisa, mas que ainda não é uma autoconsciência livre, com potência universal de compreensão da realidade na sua totalidade. Em síntese, por meio do medo absoluto, do serviço e do trabalho, a consciência servil volta a encontrar a si mesma e se converte em seu próprio sentido, em consciência livre, e uma vez adquirido sua liberdade, sua autonomia, ela se mostra capaz de empreender a larga experiência que a conduzirá a possibilidade concreta de um reconhecimento mais verdadeiro, recíproco, embora aqui ainda lhe faltem os pressupostos sociais e culturais, nos quais o ser para um outro do indivíduo seja desenvolvido, isto é, falta-lhe o reconhecimento da outra consciência, necessário para efetivação de uma sociedade mais livre, igual e justa.

Um elemento positivo do pensamento de Hegel, na Fenomenologia do Espírito, é, como vimos, a afirmação do trabalho como autoformação da consciência, como autocriação do homem. Nos Manuscritos Econômico-Filosóficos de 1844 (Ökonomischphilosophische Manuskripte aus dem Jahre 1844), Marx vê na Fenomenologia do Espírito, de Hegel, uma grande realização, dado que Hegel concebe a "autocriação" do homem como um processo, porque depreende a essência do trabalho e porque evidencia o homem objetivo "como resultado de seu próprio trabalho". Hegel, no entanto, como ressalta Marx, reconhece apenas o lado positivo do trabalho, não o seu aspecto negativo. Desse modo, para Hegel, como observa Marx nessa obra, a superação do ${ }^{358}$ Ibid., p. 115.

\begin{tabular}{|l|l|l|l|l|}
\hline Q Ronista Dialectus & Ano 3 & n. 8 & Janeiro - Agosto 2016 & p. 16-32 \\
\hline
\end{tabular}


estranhamento, da alienação (negativa), na esfera da consciência, surge como um ato puramente formal, abstrato, que deixa, na verdade, seu objeto (o próprio estranhamento) persistir no mundo real. Essa obra, em que Marx faz essa alusão ao aspecto positivo do trabalho em Hegel, publicada pela primeira vez em russo em 1932, foi resultado dos estudos sobre os economistas clássicos ingleses e franceses, entre eles, Smith, Ricardo, Mill, Say, Sismondi, Malthus, Lauderlade e Skarbek, feitos por Marx, durante o seu exílio em Paris no outono de 1843, mas redigida entre abril e agosto de 1844. Trata-se de uns Manuscritos não acabados, incompletos, mas que suscitaram muitas discussões e polêmicas entre os intérpretes do pensamento de Marx. Alguns, como Althusser, Bottigelli, têm tais Manuscritos como pré-marxistas, não científicos, tido como escritos de caráter metafísicos, filosófico-abstratos ou antropológicos. Já outros, como Lukács, Togliatti, From, tomam-nos como o germe do desenvolvimento posterior do pensamento de Marx. ${ }^{359}$ Aproximo-me desta última interpretação, já vendo os Manuscritos como o germe da base fundamental do pensamento de Marx, centrado na crítica à economia política, à especulação (à dialética hegeliana) e à política democrático-burguesa (à política dos neo-hegelianos, dos liberais etc). No que tange à crítica da economia política-clássica, Marx pretende nesses Manuscritos revelar o caráter ideológico da economia política clássica, na medida em que esta toma, por um lado, a produção de forma abstrata, geral, encobrindo a sua base, que é a propriedade privada, e, por outro, vê o trabalho apenas como atividade exterior, produtiva, escondendo a sua forma específica de trabalho estranhado como produto histórico próprio da sociedade capitalista moderna. A economia política não compreende as "interconexões do movimento histórico" da realidade social, porque ela, explica Marx, "parte do fato dado e acabado da propriedade privada. Não nos explica o mesmo. Concebe o processo material da propriedade privada, como ele ocorre na realidade, em fórmulas gerais e abstratas, que passam a valer como leis para ela. Não concebe estas leis, isto é, não demonstra como elas derivam da essência da propriedade privada. A economia política não nos fornece uma explicação sobre o fundamento da divisão entre o trabalho e o capital, entre capital e terra. Quando ela, por exemplo, determina a relação entre o salário e o lucro do capital, o que lhe vale como fundamento último é o

\footnotetext{
${ }^{359}$ Cf. Mandel, Ernest. A Formação do Pensamento Econômico de Karl Marx. Rio de Janeiro: Zahar Editores, 1980.
}

\begin{tabular}{|l|l|l|l|l|}
\hline Rovista Dialectus & Ano 3 & n. 8 & Janeiro - Agosto 2016 & p. 16-32 \\
\hline
\end{tabular}


interesse dos capitalistas; isto é, ela supõe o que deveria desenvolver." ${ }^{360}$ Marx critica duramente aqui a economia política, que, ao reconhecer apenas o lado produtivo do trabalho enquanto produtor de riqueza, oculta nele, no entanto, o estranhamento e a exploração que está na base da sociedade industrial moderna e, em geral, em toda formação social com suporte na propriedade privada dos meios de produção.

Marx parte sua análise não como faz a economia política, a partir de uma produção em geral, abstrata, a-histórica, mas de uma dada forma particular da produção, quer dizer, da produção capitalista moderna, dos fatos econômicos da sociedade burguesa, em que o "trabalhador se torna tanto mais pobre quanto mais riqueza produz, quanto mais a sua produção aumenta em poder e extensão. $\mathrm{O}$ trabalhador se torna uma mercadoria tão mais barata quanto mais mercadorias cria. Com a valorização do mundo das coisas aumenta em proporção direta a desvalorização do mundo dos homens. $\mathrm{O}$ trabalho não produz somente mercadorias; ele produz a si mesmo e ao trabalhador como uma mercadoria, e isto na medida em que produz, de fato, mercadorias em geral." ${ }^{\text {361 }}$ Marx enaltece, porém, inicialmente, Smith e Ricardo, por terem reconhecido, como substância de toda a riqueza, não só o trabalho agrícola - como os Fisiocratas - mas o trabalho em geral como a "essência subjetiva" da riqueza; além disso, por terem apreendido a propriedade privada como um produto da atividade humana. Marx menciona, nesse contexto, Engels, que, em seus Esboços de uma Crítica da Economia Política (1844), tinha denominado Adam Smith de o Lutero economista, comparando o último - que interiorizou a religião - com o primeiro - que suprimiu a "objetividade externa e sem espírito" da riqueza pródiga. Todavia, Marx denuncia aqui a economia política que toma o trabalho como a verdadeira fonte da produção, da riqueza, mas nada lhe atribui, concedendo tudo ao capital, à propriedade privada. A economia política não se interessa pela condição humana do trabalhador, pelas consequências negativas do trabalho para o trabalhador. A ela só interessa o trabalhador como mercadoria, que tem um valor, que varia de acordo com a lei da oferta e da procura; ou seja, só interessa como trabalhador ativo, produtivo, enquanto está a trabalhar, e não como ser humano em sua totalidade. A lógica da economia política é o cinismo, pois, ela tem o trabalhador como "um homem livre", embora o produza como mercadoria, reduzindo-o

\footnotetext{
${ }^{360}$ Marx, K. Die entfremdete Arbeit. In: Ökonomisch-philosophische Manuskripte aus dem Jahre 1844. Marx/Engels, Werke (MEGA), Bd. 40. Dietz Verlag, Berlin, 1990, p. 510.

${ }^{361}$ Ibid., p. 511.
}

\begin{tabular}{|l|l|l|l|l|}
\hline Qevista Dialectus & Ano 3 & n. 8 & Janeiro - Agosto 2016 & p. 16-32 \\
\hline
\end{tabular}


a um ser espiritual e fisicamente desumanizado. Essa negligência do lado humano decorre da acepção básica da economia política, que supõe ser a propriedade privada um resultado da liberdade, um atributo essencial da natureza humana, abstraindo, assim, a condição degradante do trabalhador no âmbito da sociedade com base na propriedade privada dos meios de produção. Desse modo, diz Marx, “a economia nacional não conhece, por conseguinte, o trabalhador desocupado, o homem que trabalha, na medida em que ele se encontra fora da relação de trabalho. O homem que trabalha, o ladrão, o vigarista, o mendigo, o desempregado, o faminto, o miserável e o criminoso, são figuras de homens que não existem para ela, mas só para outros olhos, para os do médico, do juiz, do coveiro, do administrador da miséria, fantasmas que se situam fora de seu domínio."362

A partir do momento em que o trabalho é considerado, para os economistas clássicos, como a "essência subjetiva" da propriedade privada, como o criador da riqueza, segue-se que a "divisão do trabalho" é apreendida como principal motor da produção. Contudo, os economistas clássicos são confusos acerca da natureza da “divisão do trabalho". Assim, por exemplo, para A. Smith, a "divisão do trabalho" é decorrência da "faculdade de troca", da propensão que o homem tem para trocar, negociar e permutar umas coisas, pois pela permuta o homem adquire o que precisa para se manter vivo. Para J. B. Say, a "divisão do trabalho" é consequência da troca, pois sem ela não haveria produção. Já para Skarbek, a causa que impulsiona um homem a prestar seus serviços a outro é o interesse próprio. S. Mill concebe, por sua vez, o comércio - como conversão invertida - enquanto resultado da "divisão do trabalho". A esta altura, eles se contradizem, embora todos estejam em consonância ao sustentar a conexão mútua entre a "divisão do trabalho" e a acumulação de riqueza, bem como ao defender que só a propriedade livre de "preconceitos locais e políticos" poderia encerrar uma "divisão do trabalho" ampla e economicamente compensadora. Para eles, em última instância, a "divisão do trabalho", baseada na troca, é absolutamente indispensável à sociedade. Contrariando essas posições, Marx sustenta que os economistas clássicos confundem o caráter social do trabalho, indispensável à sociedade, com a divisão imposta ao mesmo, pois pode-se postular a superação do trabalho estranhado por ser, precisamente, possível contrapor o caráter social do trabalho à divisão forçado do mesmo, por conseguinte, quando a atividade deixa de ser

${ }^{362}$ Ibid., p. 523-524.

\begin{tabular}{|l|l|l|l|l|}
\hline Qovista Dialectus & Ano 3 & n. 8 & Janeiro - Agosto 2016 & p. 16-32 \\
\hline
\end{tabular}


regulada com base na propriedade privada e na troca forçada, ela adquire o caráter de atividade do homem como ser genérico. Levando, pois, em consideração essas reflexões, Marx critica severamente a economia política que, ao reconhecer o lado positivo, exterior e produtivo do trabalho enquanto produtor de riqueza, ocultou o estranhamento que está na base da sociedade industrial moderna e, em geral, em toda formação social com suporte na propriedade privada dos instrumentos de produção. No âmbito da sociedade capitalista, cuja base é a propriedade privada, produz-se o fenômeno geral do estranhamento, pelo qual as forças e os produtos se subtraem ao controle e ao poder dos indivíduos, transformando-se em forças contrapostas aos homens. Nessa sociedade, o trabalho, portanto, manifesta-se ontologicamente de forma estranhada. Marx destaca quatro conexões em que ocorre esse fenômeno do estranhamento: a relação estranhada do trabalhador com seu produto, a do trabalhador com sua própria atividade (com o próprio trabalho), a do trabalhador com sua vida genérica e, por fim, a do trabalhador com outros homens.

Ao investigar os nexos causais da produção burguesa, Marx descobre que o produto do trabalho separa-se do trabalhador, converte-se em objeto alheio, torna-se estranho a ele, adquire uma existência própria que ele não pode controlar. Diz Marx: “o objeto que o trabalho produz, o seu produto, se lhe defronta como um ser estranho, como um poder independente do produtor." 363 O produto - resultado da objetivação do trabalho humano - deixa de ser, para o trabalhador, seu próprio ser objetivado, para ser apenas um objeto estranho que o enfrenta e o escraviza. $\mathrm{O}$ objeto, produto da atividade humana, produzido pelo trabalho, volta-se contra o seu produtor e passa a dominá-lo, assim como o homem, que produz Deus, mas é dominado por Ele. Marx compara o estranhamento do trabalho com o estranhamento religioso: "Quanto mais o homem põe em Deus, tanto menos ele retém em si mesmo." Da mesma forma: “O trabalhador encerra sua vida no objeto; mas agora ela não pertence mais a ele, mas sim ao objeto. Por conseguinte, quanto maior for esta atividade, tanto mais sem-objeto é o trabalhador." E mais: "a vida que ele concedeu ao objeto se lhe defronta hostil e estranha." ${ }^{364} \mathrm{O}$ trabalhador objetiva sua vida no objeto; porém, agora esta não lhe pertence, mas ao objeto. Assim, quanto mais objetos o trabalhador produzir, tanto menos pode dele se apropriar e mais se subjuga ao domínio de seu produto; "quanto

\footnotetext{
363 Ibid., p. 511.

364 Ibid., p. 512.
}

\begin{tabular}{|c|c|c|c|c|}
\hline Rovista Dialectus & Ano 3 & n. 8 & Janeiro - Agosto 2016 & p. $16-32$ \\
\hline
\end{tabular}


mais bem formado o seu produto, tanto mais deformado ele [o trabalhador] fica; quanto mais civilizado o seu objeto, mais bárbaro o trabalhador". ${ }^{365}$ A perda do objeto produzido, da produção dos meios necessários à própria produção, enfim, de tudo o que significa produção pelo trabalho humano, consiste na explicação do estranhamento do trabalhador em relação a seu produto. Na medida em que o produto é estranho ao trabalhador, o próprio trabalho se torna trabalho estranhado, trabalho alheio a ele; o próprio trabalho se converte em atividade que produz deformação e unilateralização do trabalhador, de maneira que o trabalhador não se realiza, mas se nega a si mesmo. $\mathrm{O}$ trabalho é estranhado porque se torna uma atividade exterior ao trabalhador, é forçado, que o esvazia de sua natureza humana, que é criativa, livre e consciente. A relação do trabalhador com seu trabalho, com sua atividade, é "como uma atividade estranha não pertencente a ele, a atividade como miséria, a força como impotência, a procriação como castração. A energia espiritual e física própria do trabalhador, sua vida pessoal pois o que é vida senão atividade - como uma atividade voltada contra ele mesmo, independente dele, não pertencente a ele. $\mathrm{O}$ estranhamento-de-si, tal qual acima o estranhamento da coisa." ${ }^{366}$ Nessa atividade específica, que é repetitiva, fatigante e negadora da essência humana, o trabalhador, enfatiza Marx: "não se afirma, portanto, em seu trabalho, mas nega-se nele, que não se sente bem, mas infeliz, que não desenvolve nenhuma energia física e espiritual livre, mas mortifica sua physis [ seu corpo] e arruína o seu espírito." ${ }^{367}$ Por isso, o trabalhador só pode sentir-se em si fora do trabalho, porque neste está fora de si; agora, sua realização evidencia-se nas funções puramente animais - comer, beber, procriar-se etc. - Marx acentua: o elemento humano torna-se animal, e o animal, humano.

Desse modo, quando o trabalhador se confronta com o trabalho estranhado como uma atividade não típica de sua espécie, não própria de seu gênero - o seu ser genérico (tanto no que diz respeito à sua natureza física como as suas faculdades espirituais) converte-se num ser alheio a ele próprio. De fato, o trabalho - enquanto atividade livre e consciente, que especifica a generidade do homem e o distingue do animal - lhe é negado e se transforma em simples atividade de subsistência (próxima a do animal) e contraposta aos demais seres humanos. Na sociedade capitalista, o trabalho

\footnotetext{
365 Ibid., p. 513.

366 Ibid., p. 515.

367 Ibid., p. 514.
}

\begin{tabular}{|c|c|c|c|c|}
\hline Rovista Dialectus & Ano 3 & n. 8 & Janeiro - Agosto 2016 & p. $16-32$ \\
\hline
\end{tabular}


deixa, portanto, de ser uma atividade livre e consciente (atividade positiva) e se torna uma atividade estranhada, perniciosa, deletéria, morta, imposta, repetitiva, fatigante (atividade negativa), que nega a essência humana. Enfim, o que se constata, com relação ao estranhamento do homem frente a seu produto, a sua própria atividade e a sua vida genérica, evidencia-se também na relação do homem com os outros homens. Diz Marx: "quando o homem está frente a si mesmo, defronta-se com ele o outro homem. O que é produto da relação do homem com o seu trabalho, produto de seu trabalho e consigo mesmo, vale como relação do homem com outro homem". ${ }^{368}$ Este momento evidenciase, por um lado, pelo fato de que certo número de homens produz para outros e por isso não tem o controle sobre o produto de seu próprio trabalho; por outro, pelo fato de um número reduzido de homens - os capitalistas - que não trabalham, se apropriarem do trabalho alheio. Desse modo, podemos dizer que tanto os trabalhadores como os capitalistas são estranhos um em face do outro; contudo, as consequências são diferentes: o estranhamento para o trabalhador manifesta-se como miséria, sofrimento e desumanização, enquanto para o capitalista, como riqueza, deleite e satisfação. Diz Marx: "O trabalho produz maravilhas para os ricos, mas produz privação para o trabalhador. Produz palácios, porém cavernas para o trabalhador. Ele produz beleza, porém deformação para o trabalhador. [...] Ele produz espírito, porém produz imbecilidade, cretinismo para o trabalhador."369 Frente ao cinismo do "homem livre", advogado pela economia clássica, Marx sustenta que a existência do trabalhador, no âmbito da propriedade privada, encontra-se restrita às mesmas condições da existência de qualquer outra mercadoria, e quando há uma extensa "divisão do trabalho", a atividade do trabalhador torna-se repetitiva e mecânica. Se a sociedade vier a diminuir sua riqueza, o trabalhador e o capitalista sofrem danos, o primeiro "sofre em sua existência", enquanto o segundo "no ganho de seu mamon morto [nos lucros de sua riqueza morta]"370. Porém, ninguém sofre tão cruelmente com seu declínio como os trabalhadores, e mesmo que a riqueza social aumente, o resultado inevitável para o trabalhador é o trabalho excessivo e a morte prematura, a degradação, a sujeição ao capital que se acumula em ameaçadora oposição a ele; "a nova concorrência, a morte por fome ou mendicidade de uma parte dos trabalhadores" ${ }^{\text {371; }}$ o trabalhador não tem

\footnotetext{
${ }^{368}$ Ibid., p. 517-518.

${ }^{369}$ Ibid., p. 513.

${ }^{370}$ Ibid., p. 473.

${ }^{371}$ Ibid., p. 474.
}

\begin{tabular}{|c|c|c|c|c|}
\hline Rovista Dialectus & Ano 3 & n. 8 & Janeiro - Agosto 2016 & p. $16-32$ \\
\hline
\end{tabular}


apenas de lutar pelo meio físico de subsistência, deve ainda lutar para alcançar trabalho, isto é, "pela possibilidade, pelos meios de poder efetivar sua atividade." 372 Até mesmo o singelo aumento dos salários não constitui como solução adequada, pois ele não passa de uma remuneração melhor de "escravos", não restituindo ao trabalhador e ao trabalho o seu valor humano; pelo contrário, estimula o apetite do capitalismo em manter e aumentar seus lucros. A "divisão do trabalho" torna o trabalhador cada vez mais dependente de um tipo particular de atividade, extremamente unilateral, que o reduz espiritual e fisicamente; longe de mitigar seu peso, se opõe a ele como competidora; a acumulação e a concentração de força, que parecem sancionar maior racionalização, se convertem em superprodução e findam por deixar sem trabalho grande parte dos trabalhadores, ou "numa condição de penúria ou de fome".

É importante ressaltar que, nos Manuscritos de 1844, o trabalho é tratado por Marx tanto em sua acepção particular, quanto em sua concepção geral. ${ }^{373} \mathrm{Em}$ sua acepção particular, o trabalho, estruturado no modo de ser capitalista, é, como mostrado anteriormente, trabalho estranhado. Na acepção geral, o trabalho é tomado como a determinação ontológica fundamental da humanidade, o modo realmente humano de existência, isto é, a atividade fundante da produção e reprodução da vida humana - a atividade primária, necessária e natural do homem. É importante destacar ainda que Marx não critica o trabalho enquanto tal, mas apenas uma dada forma particular do trabalho, isto é, o momento do estranhamento num trabalho específico, dado que a essência humana (que não é uma abstração, nem dada naturalmente, mas uma construção do próprio homem) se realiza no trabalho, quer dizer, o trabalho é a essência do homem. Precisamente, o que especifica a essência de um ser vivo é a forma como vive, produz e reproduz a vida. Marx afirma: "No modo da atividade vital encontra-se o caráter inteiro de uma species [espécie], seu caráter genérico, e a atividade consciente livre é o caráter genérico do homem." 374 A atividade dos demais animais se reduz exclusivamente ao consumo dos objetos de suas próprias necessidades imediatas. Essa forma de atividade, mesmo a mais deslumbrante, é unilateral, limitada, repetição instintiva e quase mecânica, restrita e impulsionada de acordo com a própria estrutura

\footnotetext{
372 Ibid., p. 473.

${ }^{373}$ Cf. Chagas, Eduardo F. "A natureza dúplice do trabalho em Marx: trabalho útil-concreto e trabalho abstrato." In: Outubro - Revista do Instituto de Estudos Socialistas. No 19. Campinas - São Paulo, 2011.

${ }^{374}$ Marx, K. Die entfremdete Arbeit. In: Ökonomisch-philosophische Manuskripte aus dem Jahre 1844. Marx/Engels, Werke (MEGA), Bd. 40. Dietz Verlag, Berlin, 1990, p. 516.
}

\begin{tabular}{|l|l|l|l|l|}
\hline Gonista Dialectus & Ano 3 & n. 8 & Janeiro - Agosto 2016 & p. 16-32 \\
\hline
\end{tabular}


orgânica e, por isto, norteada apenas a uma necessidade específica. Frisa Marx: "É verdade que também o animal produz. Constrói para si um ninho, habitações, como a abelha, castor, formiga etc. Mas só produz o que necessita imediatamente para si ou sua cria; produz unilateralmente [...]; o animal só produz a si mesmo [...]. O animal forma apenas segundo a medida e a carência da species [espécie] a que pertence. ${ }^{375}$ Ao contrário, a atividade do homem é radicalmente diversa da dos animais, pois é livre e consciente; ela destrói um mundo objetivo e manipula a natureza de acordo com a própria vontade humana. Através do trabalho, o homem manifesta-se como ser genérico, suplanta a atividade muda dos animais, produz sua existência de um ser universal e livre; por isso, o homem só se constitui como ser universal e livre, na medida em que é sujeito de uma atividade livre e consciente. Daí que o homem, menciona Marx: "produz universalmente; [...] produz livre da carência física, e só produz, primeira e verdadeiramente, na liberdade de tal necessidade; [...] reproduz a natureza inteira; [...] se defronta livremente com o seu produto [...], sabe produzir segundo a medida de qualquer species [espécie], e sabe considerar, por toda a parte, a medida inerente ao objeto; o homem também forma, por conseguinte, segundo as leis da beleza." ${ }^{376}$ É com o trabalho que o homem desenvolve a sua consciência e as suas capacidades técnicas e espirituais; torna-se ser genérico, isto é, supera a individualidade fechada dos animais, produz a sua existência e cria a consciência do seu ser social, chegando à consciência de ser universal e livre. O trabalho, como objetivação e autodesenvolvimento humano, como automediação necessária do homem com a natureza, constitui a esfera ontológica fundamental da existência humana, e, portanto, o suporte último de todos os tipos de atividade. Através dele, ocorre uma dupla transformação: a da natureza exterior e inorgânica e a da própria natureza do homem. Os objetos e as formas da natureza são transformados em meio, em objeto de trabalho. Esses objetos, da mesma forma produtos do trabalho, são, por isso mesmo, objetos humanizados: não são simples natureza, mas natureza humanizada. O produto do trabalho é o trabalho que se fixou num objeto, que se transformou em coisa física, "é a objetivação do trabalho. A efetivação do trabalho é a sua objetivação." 377 A objetivação é uma conditio sine qua non da universalidade do trabalho, que traz necessariamente o

\footnotetext{
375 Ibid., p. 517.

376 Ibid., p. 516.

377 Ibid., p. 512.
}

\begin{tabular}{|c|c|c|c|c|}
\hline Rovista Dialectus & Ano 3 & n. 8 & Janeiro - Agosto 2016 & p. $16-32$ \\
\hline
\end{tabular}


momento da alienação; esta incorre, pois, num momento positivo em que o produtor, através de sua atividade, entra em conexão com o produto de seu trabalho e com os outros homens. Portanto, o homem só pode afirmar-se como ser genérico, mediante a atuação conjunta dos homens e pela manifestação de todas as suas forças genéricas, o que, a princípio, só pode ser feito sob a forma de alienação.

A alienação (positiva) no trabalho, enquanto momento necessário da objetivação, independente de todas as formas de sociabilidade, é a esfera ontológica fundamental da existência humana. A alienação é essencial para que o homem se afirme como ser humano, dado que seu produto confirma sua atividade objetiva, "a sua atividade como a de um ser objetivo." O objeto do trabalho é, pois, consequência da objetivação do gênero humano, uma vez que o homem se desdobra não apenas na consciência, intelectualmente, mas também ativamente, na realidade concreta; por isso, o homem contempla a si não apenas nas formas espirituais objetivadas, como também no mundo material que ele criou. O poder que tem o homem de objetivar-se, através de seu trabalho, é especificamente humano; manifesta-se como alienação (positiva) de sua vida genérica e encerra características genuinamente humanas. É, pois, insustentável pensar a vida humana sem o trabalho, sem objetivação. Como é sabido, todo processo de objetivação traz intrínseco o momento da alienação; porém, nem toda alienação é um estranhamento. Somente numa dada forma particular da sociabilidade, cuja base é a propriedade privada dos meios de produção, o processo de objetivação traz consigo o momento do estranhamento, onde a objetivação surge como "perda do objeto", a atividade produtiva torna-se atividade que mutila e desumaniza o homem. Pode-se evidenciar que o homem, ao objetivar-se na cultura, na arte, no Estado, na política, ao mesmo tempo se aliena. A alienação é, portanto, um momento necessário da objetivação, ou melhor, um momento insuperável da existência humana. Precisamente, uma das grandes dificuldades do marxismo contemporâneo consiste em não depreender a distinção ontológica fundamental entre objetivação, alienação e estranhamento. A alienação, como já disse, a partir das análises de Marx, é um momento indispensável da objetivação, enquanto que o estranhamento corresponde a uma dada forma particular da objetivação, em que lhe é intrínseco o momento da perda e da despossessão do objeto pelo sujeito; ou seja, o produto do trabalho lhe aparece como algo autônomo, alheio e independente de sua atividade. A objetivação, nas condições em que o trabalho se torna “exterior ao homem”, assume um "poder estranho", que enfrenta o homem de "maneira

\begin{tabular}{|l|l|l|l|l|}
\hline Rovista Dialectus & Ano 3 & n. 8 & Janeiro - Agosto 2016 & p. 16-32 \\
\hline
\end{tabular}


hostil". Esse poder exterior - a propriedade privada, a riqueza excessiva, - é consequência inevitável do momento do estranhamento, da conexão externa entre o trabalhador e a natureza, entre o trabalhador e a si mesmo. Assim, se o resultado desse tipo de objetivação é a produção de um "poder hostil", o homem já não pode realmente “contemplar-se num mundo por ele criado", está subjugado a uma instância exterior e privada de sentido de sua própria atividade, cria um mundo irreal, submete-se a ele e com isto restringe sua própria liberdade. Para Marx, o estranhamento do trabalho, a contradição entre trabalhador (trabalho) e capitalista (capital) só será resolvida mediante a emancipação social do trabalhador e de toda a humanidade. Essa emancipação dá-se com a supressão da propriedade privada e de sua essência subjetiva, o trabalho estranhado, sobre as quais repousa o Estado moderno, que deve ser também negado, criando as condições para a apropriação social, coletiva, dos objetos e a reconciliação do homem consigo mesmo. Essa reconciliação, apropriação da essência humana pelo e para o homem, inicia-se, para Marx, no comunismo, que seria uma etapa nova na produção de coisas voltada para a realização e humanização do homem.

\section{Referências}

Chagas, Eduardo Ferreira: "Diferença entre Alienação e Estranhamento nos Manuscritos Econômico-Filosóficos (1844), de Karl Marx", in: Revista Educação e Filosofia. Uberlândia: Universidade Federal de Uberlândia, Junho/Dezembro de 1994, vol. $8, \mathrm{n}^{\circ} 16$, p. 23-33.

O Método Dialético de Marx. In: Marxismo, Educação e Luta de Classe. Fortaleza: EdUECE/IMO/SINTSEF, 2008.

"O Pensamento de Marx sobre a Subjetividade", in: Subjetividade e

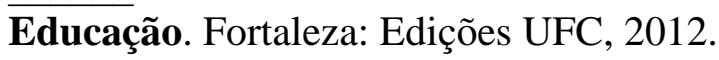

. "A natureza dúplice do trabalho em Marx: trabalho útil-concreto e trabalho abstrato.” In: Outubro - Revista do Instituto de Estudos Socialistas. No 19. Campinas - São Paulo, 2011.

“"A crítica da política em Marx". In: Revista Dialectus. N 5, Fortaleza:, 2014.

Giannotti, J. A. Certa Herança Marxista. São Paulo: Companhia das Letras, São Paulo, 2000.

\begin{tabular}{|l|l|l|l|l|}
\hline Qonista Dialectus & Ano 3 & n. 8 & Janeiro - Agosto 2016 & p. 16-32 \\
\hline
\end{tabular}


Hegel, G. F. W. Phänomenologie des Geistes. Hauptwerke in sechs Bänden, Vol. 2 Organização de Wolfgang Bonsiepen e Reinhard Heede. Hamburgo: Wissenschaftliche Buchgesellschaft Darmstadt, 1999.

Mandel, Ernest. A Formação do Pensamento Econômico de Karl Marx. Rio de Janeiro: Zahar Editores, 1980.

Marx, K. Kritik der politischen Ökonomie. In: Marx/Engels, Werke (MEGA), Bd. 13..Berlin: Dietz Verlag, 1983.

Die entfremdete Arbeit. In: Ökonomisch-philosophische Manuskripte aus dem Jahre 1844. Marx/Engels, Werke (MEGA), Bd. 40. Dietz Verlag, Berlin, 1990.

Marx, K. Lohnarbeit und Kapital. In: Marx/Engels, Werke (MEGA), Bd. 6. Dietz Verlag, Berlin, 1990.

Das Kapital. In: Marx/Engels, Werke (MEGA). Berlin: Dietz Verlag, 1962, v. 23, livro 1, cap. 1 .

Capítulo VI Inédito de O Capital - Resultados do Processo de Produção Imediata. São Paulo: Editora Moraes, s/d.

\begin{tabular}{|l|l|l|l|l|}
\hline Qenista Dialectus & Ano 3 & n. 8 & Janeiro - Agosto 2016 & p. 16-32 \\
\hline
\end{tabular}

